\title{
Spatiotemporal distribution of rabies in Arctic foxes in Greenland
}

\author{
Katrine Raundrup ${ }^{1,2}$ - Charlotte M. Moshøj ${ }^{2,3}$ • Sanne E. Wennerberg ${ }^{4}$. \\ Christian M. O. Kapel ${ }^{5}$
}

Received: 21 March 2014 /Revised: 25 March 2015 / Accepted: 27 March 2015 / Published online: 1 May 2015

(C) Springer-Verlag Berlin Heidelberg 2015

\begin{abstract}
The temporal occurrence, spatial distribution, spread, and prevalence of rabies in Arctic foxes, Vulpes lagopus, in Greenland were studied using historical observations from 1969 to 2011 and survey data collected in the winters 1992 and 1993. Regionally, the prevalence of rabies ranged between 0 and $7.1 \%$. Wavelet analysis was used to identify periodicities in the abundance of rabies cases based on the historical observations. No general length of the cyclic interval of rabies occurrences in Greenland could be demonstrated. The frequency of outbreaks was found to be variable but can be grouped as short (less than 5 years), medium (5-10 years), and long (more than 10 years). Moreover, rabies outbreaks in neighboring regions were found to be more closely correlated compared to regions further apart. In West Greenland, the temporal outbreaks of rabies were found to occur along a north-south trajectory.
\end{abstract}

Communicated by M. Artois

Katrine Raundrup

kara@natur.gl

1 Greenland Institute of Natural Resources, P. O. Box 570, 3900 Nuuk, Greenland

2 Department of Bioscience, Aarhus University, Frederiksborgvej 399, 4000 Roskilde, Denmark

3 Department of Environmental, Social and Spatial Change, Roskilde University, Universitetsvej 1, P.O. Box 260,

4000 Roskilde, Denmark

4 Department of Fisheries, Hunting and Agriculture, P. O. Box 280, 3952 Ilulissat, Greenland

5 Department of Plant and Environmental Sciences, University of Copenhagen, Thorvaldsensvej 40, 1871 Frederiksberg C, Denmark
Keywords Vulpes lagopus · Arctic fox · Greenland · Rabies · Spatiotemporal dynamics

\section{Introduction}

Rabies is a disease considered to be endemic throughout most parts of the Arctic (WHO 2004; MacDonald et al. 2011). It is caused by a virus (Lyssavirus, Rhabdoviridae) infecting the central nervous system causing encephalopathy and is often fatal for the affected animal. The virus is transmitted via the saliva through open wounds when being bitten or alternatively over mucous membranes (Krebs et al. 1995; Hankins and Rosekrans 2004). Rabies has a wide host spectrum among mammals, rendering it a severe zoonosis (Leung et al. 2007; Jackson 2008).

The Arctic fox (Vulpes lagopus) is considered to be the main vector of rabies in circumpolar Arctic although other arctic mammals may occasionally become infected (Rausch 1958; Odegaard and Krogsrud 1981; Mørk and Prestrud 2004; Nadin-Davis et al. 2012). Arctic foxes have a circumpolar distribution (Angerbjörn et al. 2004) and they live as opportunistic predators and scavengers in coastal as well as inland habitats (Kapel 1999; Meinke et al. 2001; Pagh and Hersteinsson 2008).

In Greenland, rabies has been found in Arctic fox, caribou Rangifer tarandus, sledge dog and domestic dog Canis familiaris, sheep Ovis aries (Leisner 2002), horse Equus caballus (Ann. 2001), and domestic cat Felis catus (Christensen et al. 2008). A rabies-like outbreak in dogs was described in 1859/1860 (Tabel et al. 1974; Bjerregaard and Zoffmann 1986) and although rabies has most likely always been endemic to Greenland, a clear description in dogs and Arctic foxes was not done before 1959 (Lassen 1962). 
Studies on rabies virus have shown that the virus strain found in the Arctic has emerged within the last 200 years and has spread quickly over a wide area (Nadin-Davis et al. 2012). Prevalence of rabies in Arctic foxes display fluctuating oscillations reflecting the cyclic nature and abundance in the Arctic fox populations (Elmhagen et al. 2011). Further, the high degree of genetic similarity between virus isolates from Greenland and North America (Mansfield et al. 2006; Kuzmin et al. 2008) imply that reintroductions of the virus through migration are possible with Arctic foxes crossing the Baffin Bay/Davis Strait in winters with covering sea ice (Leisner 2002; Geffen et al. 2007; Nadin-Davis et al. 2012). Additionally, Arctic foxes might even cross the Greenland Sea from Svalbard and reinfect foxes in East and Northeast Greenland (Leisner 2002). This is further supported by genetic studies of Arctic foxes that imply low degree of genetic diversity between foxes in North America, northern Greenland, and Svalbard (Geffen et al. 2007; Norén et al. 2011a).

This present paper investigates and contrasts the temporal occurrence, spatial distribution, and spread of rabies in Greenlandic Arctic foxes based on historical observations from 1969 to 2011. Further, it presents the results of a prevalence study conducted during the winters of 1992 and 1993.

\section{Materials and methods}

The spatial analysis of the occurrence of rabies was based on samples from seven geographical regions: (1) South Greenland, (2) Nuuk, (3) Kangerlussuaq-Sisimiut, (4) Disko Bay, (5) Upernavik, (6) Northwest Greenland, and (7) East Greenland (Fig. 1). The sampling regions differ in size but were chosen based on geographic features and in-between distance that naturally divides them. It should be noted that regions 1 and 2 are areas where sledge dogs are prohibited by law, while sledge dogs are present in the remaining five regions (Fig. 1).

The presented data on rabies in Arctic foxes in Greenland comprises both historical sources and a multi-site prevalence study conducted over a 2-year period.

\section{Historical sources}

The historical data collected in 1969-2011 are based on shot animals with suspected rabies infection. Thus, local hunters have shot foxes with abnormal behavior and delivered these to the local authorities. The animals were shipped frozen to the Institute of Viral Research, Lindholm, Denmark, for diagnosis. The diagnostic results were then provided to the Veterinary and Food Authority of Greenland, the institution responsible for maintaining records of rabies in Greenland. In addition to the diagnostic result, information on location and species (e.g., Arctic fox or dog) are included in the data. Since
Fig. 1 Spatiotemporal distribution of rabies in seven sampling regions in Greenland: (1) South Greenland, (2) Nuuk, (3) Kangerlussuaq-Sisimiut, (4) Disko Bay, (5) Upernavik, (6) Northwest Greenland, and (7) East Greenland. In addition, periodicity of rabies on a Greenland scale is presented. For each of the regions, the wavelet power spectrums are presented (furthest to the left) as period (in years) between cycles as a function of time (years). The color scale indicates the strength of periodicity and ranges from blue (weak) to red (strong). Contour lines indicate statistically significant periodicities $(p<0.05)$. The line plot depicts the number of rabies-positive Arctic foxes $(N)$ as a function of time (year)

1991, suspected rabid foxes tested negative for rabies have been included in the records. During this period, the majority $(67 \%)$ of the suspected rabid foxes submitted by hunters tested positive for rabies. For the purpose of this study, only Arctic foxes positive for rabies have been included.

Samples collected for a prevalence study (1992-1993).

For the prevalence study, a total of 266 Arctic foxes were caught in Greenland by local hunters in the years 1992 and 1993. Of these, 245 foxes were caught in traps for subsistence purposes by the local hunters and 21 as a governmental initiative to manage Arctic fox populations locally (Kapel and Nansen 1996). Although inexperience of younger foxes and foxes infected with rabies may eventually predispose them to be captured, trapping may offer a relatively objective way of collecting individuals. Shooting tends to favor size or color depending on the preference of the hunter, but the foxes shot in the present material were killed without preference for size or color simply to control populations locally. Therefore, even though the number of collected Arctic foxes is limited, composition of the populations might be represented well. The Arctic foxes originated from seven different geographical regions as illustrated by Fig. 1 and Table 1 and were caught during two winter seasons (November-March) in 1992 and 1993. The foxes were transported to the Institute of Viral Research, Lindholm, Denmark, and kept frozen at $-20{ }^{\circ} \mathrm{C}$ for a period of 2-3 months prior to examination for rabies.

The brains of the Arctic foxes were examined for rabies by a standard fluorescent antibody test, FAT. An anti-rabies virus nucleocapsid conjugate from the Pasteur Institute (Paris, France) was used (Robles et al. 1992; Woldehiwet 2005).

\section{Wavelet analysis}

Changes in the dominant significant periodicities of the temporal occurrence of foxes with rabies across the seven geographical regions (the historical data) were examined using wavelet analysis (Cazelles et al. 2008; Mallat 2008). A wavelet analysis performs a time/frequency analysis of the signal (e.g., the number of rabid foxes), providing information on the periodic components of the signal as time progresses. The Morlet mother wavelet was utilized permitting extraction of both time-dependent amplitude and phase of the time series. 

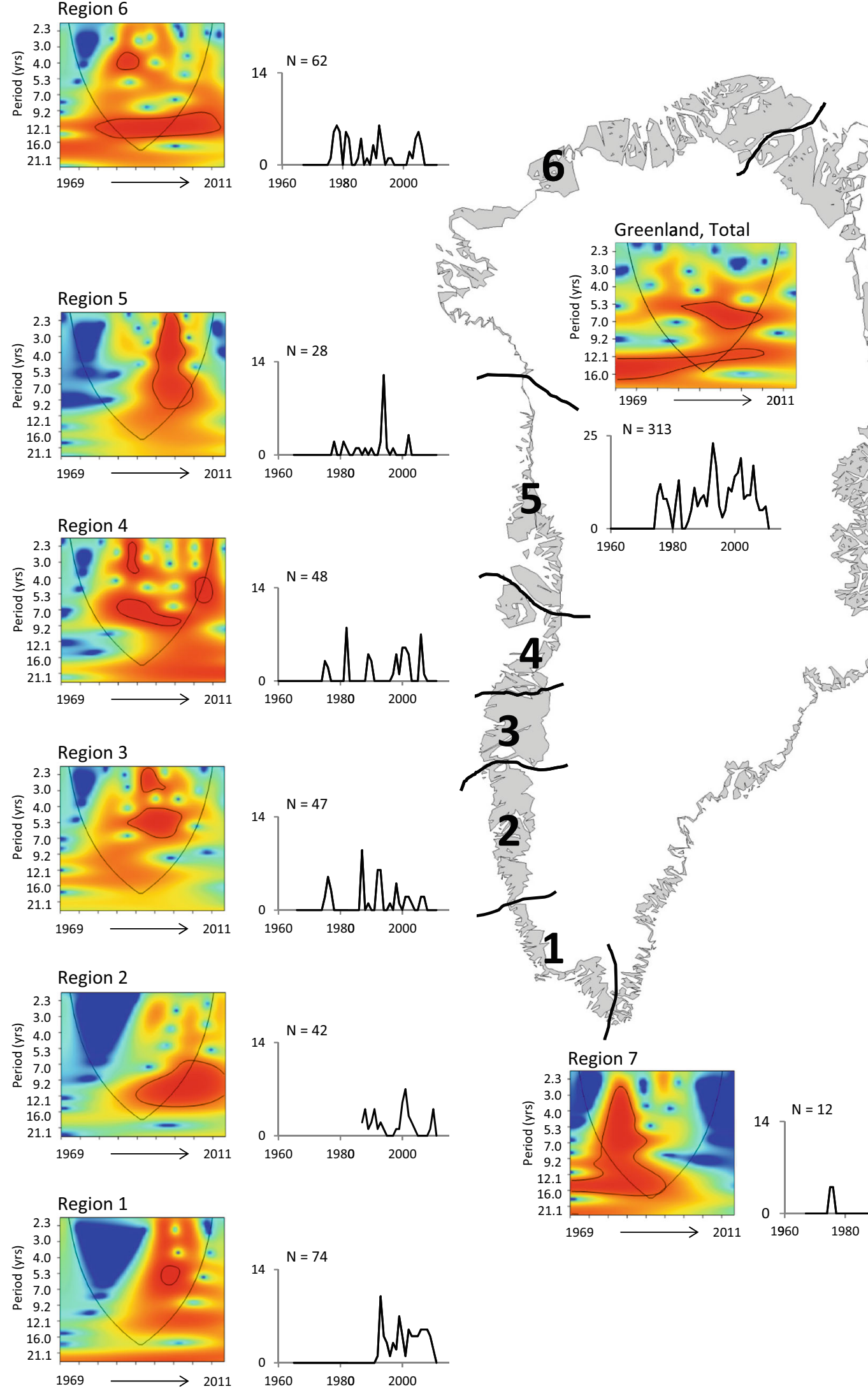
Table 1 Number of Arctic foxes examined and tested positive for rabies during the winter field campaign in 1992 and 1993

\begin{tabular}{lllll}
\hline Region & Examined & Rabies positive & \% positive \\
\hline 1 & South Greenland & 41 & 1 & 2.4 \\
2 & Nuuk & 33 & 0 & 0.0 \\
3 & Kangerlussuaq-Sisimiut & 56 & 4 & 7.1 \\
4 & Disko Bay & 0 & - & - \\
5 & Upernavik & 0 & - & - \\
6 & Northwest Greenland & 116 & 3 & 2.6 \\
7 & East Greenland & 20 & 0 & 0.0 \\
& Total & 266 & 8 & 3.0 \\
\hline
\end{tabular}

This wavelet (the Morlet mother) is often used to describe ecological time series of similar lengths to ours (Ménard et al. 2007; Mallat 2008). The visualization of a wavelet analysis (as in Fig. 1) is based on a colored wavelet power spectrum displaying the data (the periodicity of the data as a function of the time). The colors range from blue to red where blue is week periodicity and red is strong periodicity. Statistically significant periodicities are indicated by contour lines (Ménard et al. 2007; Sundelöf et al. 2013). Wavelet analyses were performed in PAST version 2.16 (Hammer et al. 2001).

\section{Correlation analyses}

To test for correlations in the number of rabies-positive foxes between neighboring regions and the strength and direction of the relationship between the number of rabid foxes and the regions, three correlation analyses were done. First, Spearman's coefficient of rank correlations (Sokal and Rohlf 2001) were calculated based on number of foxes tested positive for rabies during the period 1969-2011. This was done by correlating the number of foxes from each year with the number in the other individual regions the same year. Second, the effect of distance between regions was studied using the results from the Spearman's tests when calculating the distancedependent correlation coefficient. Data on distance between geographical midpoints along the shore line of the regions were used for calculating the linear regression coefficient. Finally, cross correlation analyses were done on yearly rabies outbreaks in neighboring regions to further study the directional spread of the disease. The correlation output (as in Fig. 3) represents individual cross correlations at different lags in time $(h)$. Rabies outbreaks in neighboring regions are either correlated with positive lags $(h>0)$ indicating that outbreaks of rabies in region $\mathrm{x}$ (southernmost region) lags outbreaks in region y (northernmost region), or correlated with negative lags $(h<0)$ in which case region y lags region $\mathrm{x}$. More than one significant $(p<0.05)$ cross correlation in the data are due to periodicities in the data (Hammer 2015). For the purpose of the latter two correlation analyses, only regions 1-6 were used in the calculations due to the low number of rabid foxes reported from East Greenland (region 7).

\section{Results}

\section{Prevalence study}

Rabies was detected in 8 of 266 Arctic foxes from the field campaign (1992-1993) resulting in a prevalence ranging between 0 and $7.1 \%$ in Greenland (Table 1). Large geographic variation in the prevalence of rabid foxes was evident since no rabies-positive foxes were caught in traps in the Nuuk area (region 2) and at the east coast of Greenland (region 7), while $7.1 \%$ of the trapped foxes in the Kangerlussuaq-Sisimiut area (region 3) were rabid.

\section{Historical data}

Over the period 1969-2011, a total of 313 Arctic foxes was recorded rabid for all seven regions (Fig. 1). The total number of records within a region ranged from 12 records in East Greenland (region 7) to 74 in South Greenland (region 1).

\section{Wavelet analyses}

The spatial and temporal pattern of recorded rabid foxes in Greenland is presented in Fig. 1. Eight wavelet analyses were performed including analyses from the seven regions as well as one on the overall Greenland scale. Visual examination of the power spectrograms did not reveal any general trend in the length of the cyclic interval of rabies occurrences throughout Greenland at the regional scale. However, the frequency of outbreaks could generally be grouped within 3 phases: short (less than 5 years), medium (5-10 years), and long (more than 10 years) (Table 2). Furthermore, a temporal difference in occurrences of the different phases was observed visually but again without a general pattern (Fig. 1). In three of the

Table 2 Length (years) of the observed cyclic phases of rabies in the different regions of Greenland

\begin{tabular}{lllll}
\hline Region & Area & Short & Medium & Long \\
\hline 1 & South Greenland & & $5-6$ & \\
2 & Nuuk & $6-14$ & \\
3 & Kangerlussuaq-Sisimiut & $2-3$ & $4-7$ & \\
4 & Disko Bay & $2-4$ & $4-9$ & \\
5 & Upernavik & & $3-10$ & \\
6 & Northwest Greenland & & $3-5$ & $9-15$ \\
7 & East Greenland & & & $3-17$ \\
& Greenland, total & & $5-7$ & $11-14$ \\
\hline
\end{tabular}

See Fig. 1 for details 
regions (i.e., 1, 2, and 5), only the medium phase length of cyclicity occurred. In regions 3,4 , and 6 , two phases of varying lengths were observed. In region 7, East Greenland, only one cyclic period was observed but the range of the cycle was large (between 3 and 17 years). However, the number of rabid foxes recorded from East Greenland was low (Fig. 1, line plot), and the cyclicity was only present in the very beginning of the rabies recording period. This early occurrence of rabies could also be detected in Northwest Greenland (region 6) where 2 main frequency periods of approximately 4 and 12 years were dominant. Rabies outbreaks in Kangerlussuaq-Sisimiut (region 3) followed a pattern with two lengths of cyclicity, namely 2-3 years and 4-7 years. In Upernavik (region 5), only one periodicity was evident resulting in cyclicity lasting $3-10$ years in the late 1980 s to 1990s corresponding to the recorded outbreak in 1994. In the Disko Bay (region 4), the wavelet analysis displayed 2 significant periods of 2-4 years in the 1980s and 4-9 years during the remaining of the time. The time series of rabies outbreaks in foxes in Nuuk was less comparable due to the later observation of the first rabid fox but had a length of the cyclic phase of 6-14 years. The South Greenland region (region 1) was found to be distinctly different from the remaining regions on the west coast, by transcending from being a region without detectable rabies to having significant cycles of 5-6 years of rabies outbreaks since the 1990s.

The periodicity of rabies outbreaks based on the wavelet power spectrogram at the Greenland scale indicates both medium (5-7 years) and long (11-14 years) lengths of cyclicity. Thus, the trends found at the regional scale correspond well with the findings at the country scale.

\section{Spread of rabies}

The Spearman's correlation index table (Table 3) and the distance-dependent rabies correlations (Fig. 2) reveal higher but nonsignificant $\left(r^{2}=0.2234, p=0.075\right)$ overall correlations

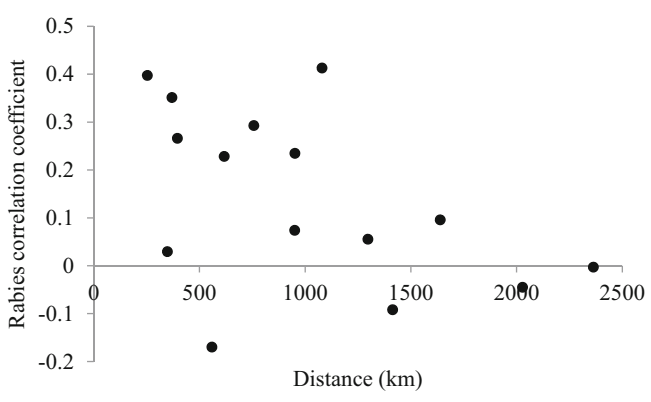

Fig. 2 Distance-dependent correlation coefficient of rabies outbreaks as a function of distance $(\mathrm{km})$ between the regions. Regions further apart show less correlation in rabies outbreaks than regions closer together

of the timing of rabies outbreaks between near neighboring regions than between geographic locations further apart. South Greenland (region 1) and Nuuk (region 2), KangerlussuaqSisimiut (region 3) and Disko Bay (region 4), and Upernavik (region 5) and Northwest Greenland (region 6) show pairwise similarities in timing of outbreaks of rabies. The correlation in rabies outbreaks between regions located closer together is further supported by the distance-dependent correlation shown in Fig. 2. There is a tendency for near neighbors to have temporal overlap in outbreaks compared to regions further apart.

Visual examination of the results from the wavelet power spectograms indicates a north-south trajectory in the spread of rabies. This is supported by the cross correlation analyses (Fig. 3) which, exempting one region only, describes the outbreaks of rabies as occurring along a north-south course. The cross correlations between regions 1 and 2, 2 and 3, and 4 and 5, along with 5 and 6 (Fig. 3a, b, d, e), are all significant with positive lag values suggesting that the outbreaks occur in the northern region of the pair before occurrences in the southern region. The only exception to this is the cross correlation between regions 3 and 4 (Fig. 3c) where the significant correlations are evident only with negative lag values. This implies that within these two regions, rabies outbreaks seem to occur in the southern region (region 3) before they are seen in the northern region (region 4). Regions 3 and 4 are geographically
Table 3 Spearman's coefficient of rank correlation matrix

\begin{tabular}{llllllll}
\hline & Region 1 & Region 2 & Region 3 & Region 4 & Region 5 & Region 6 & Region 7 \\
\hline Region 1 & - & 0.0209 & 0.0568 & 0.1300 & 0.7254 & 0.9841 & 0.2035 \\
Region 2 & 0.3513 & - & 0.0847 & 0.1409 & 0.6379 & 0.7738 & 0.9546 \\
Region 3 & 0.2927 & 0.2660 & - & 0.0083 & 0.2755 & 0.5413 & 0.2217 \\
Region 4 & 0.2346 & 0.2283 & 0.3974 & - & 0.8523 & 0.5578 & 0.1488 \\
Region 5 & 0.0552 & 0.0738 & -0.1701 & 0.0293 & - & 0.0059 & 0.5606 \\
Region 6 & -0.0031 & -0.0451 & 0.0958 & -0.0919 & 0.4128 & - & 0.8066 \\
Region 7 & -0.1978 & -0.0089 & 0.1903 & 0.2240 & -0.0912 & -0.0384 & - \\
\hline
\end{tabular}

The analyses were done on pairwise correlations of number of foxes tested positive for rabies per year during the period 1969-2011 in the different regions (1-7). Values above the diagonal are $p$ values where numbers in italics show significant similarities in timing of rabies outbreaks. Values below the diagonal are the coefficients indicating the positive or negative strength of association between the locations. For information on the location of the different regions, please refer to Fig. 1 
smaller than the neighboring regions, and this has been known to possibly influence how results should be inferred (Tinline and MacInnes 2004). Based on the outcome of our results, we therefore included two additional analyses in which rabies data from regions 3 and 4 were summed followed by cross correlations with regions 2 and 5. The results of this analysis (Fig. 3g, f, respectively) show that with the new regional boundaries, the cross correlations between regions 2 and " 3 +4 " and regions " $3+4$ " and 5 are significant with positive lags indicating that rabies outbreaks along the entire west coast of Greenland follow a north-south trajectory.

\section{Discussion}

There seems to be a general overall trend in the cyclicity of rabid foxes in Greenland with an average period of 5-10 years between outbreaks (Table 2, Fig. 1). These are significantly longer intervals than those observed in both North America and Svalbard where cyclicity of 3-5 years has been reported (Tabel et al. 1974; Nadin-Davis et al. 2008) but comparable with the 6-10 years suggested by Mørk and Prestrud (2004) for arctic populations in general. The link between the cyclic occurrence of rabies outbreaks in Arctic fox populations reported here and in related studies is often reported as being correlated to fox population density, relying in part on cyclic variations in prey abundance, e.g., rodents (Ballard et al. 2001; Dalén et al. 2005; Norén et al. 2011b). When Arctic fox populations peak in numbers, the likelihood of encounters between individuals increases once the foxes disperse (Tabel et al. 1974; Mørk and Prestrud 2004; Mørk et al. 2011). Studies on dispersal distances in Canada (Tarroux et al. 2010) and Russia (Goltsman et al. 2005) indicate that movement distances of more than a thousand kilometers are not uncommon in Arctic foxes. Such movements may effectively disperse rabies virus to large areas within relatively short time (Tabel et al. 1974). Since the rabies virus may remain infective in frozen carcasses, the etiological agent may be transmitted over extended periods of time. Thus, foxes may become exposed from scavenging on infected carcasses and reinforce a beginning epizootic (Ballard et al. 2001; Mørk and Prestrud 2004).

Although it is not possible to make definitive conclusions on the cyclicity of rabies in the Greenlandic Arctic fox populations, our results indicate that long distance dispersal of rabid foxes as a means of transmission may prevail in Greenland. The spread of rabies along a north-south gradient in West Greenland (from region 6 to region 1) will most likely include foxes dispersing over large distances carrying the virus to areas further south. Furthermore, the occurrence of rabies appears to be high in region 6 (Northwest Greenland) based both on the prevalence study and on the historical records (Fig. 1 and Table 1). The region is only separated by a narrow strait (30-40 km wide) from the northeast Canadian archipelago which may represent a transmission route for rabies by invading foxes.

Such migration may be supported by autoregressive analysis of hunting statistics (1919-1939) which identified a 3year time lag between fox population peaks in Canada (NWT/Nunavut) and Northwest Greenland (pers. comm. Charlotte Moshøj). The high degree of genetic similarities between the rabies strains in Greenland and North America (Mansfield et al. 2006; Kuzmin et al. 2008) further supports the migration of rabid foxes between the two countries.

East Greenland (region 7) stands out from the remaining regions because of the seemingly low presence of rabies (Fig. 1), where only 12 cases have been observed since the late 1960s. As the region is only sparsely populated, the probability of close fox-human encounters is low and eventual cases may not even be reported (Prestrud et al. 1992; Kuzmin et al. 2008). Furthermore, within fox populations at low densities, sporadic contacts between individual foxes will reduce the persistence of the rabies virus in the population. As rabid foxes are only infrequently reported in the area (last record 1995), infection is most likely maintained at a low endemic level by foxes performing longer migrations.

Most reports of rabid foxes are from South Greenland (region 1). Sheep farming is widespread in the region, which attracts foxes and possibly increases the number of humanfox encounters and reporting on rabid foxes.

Within the remaining regions (2-5), the temporal distribution of rabies is more uniform. The regions are all along the north-south rabies transmission route and peaks in outbreaks are delayed in time along this path.

In Greenland, the major concern regarding rabies is its zoonotic property and the fact that disease may be transmitted from the fox reservoir to the dog population. Transmission to man is most common from infected dogs which in Greenland is either the sledge dogs (in regions 3-7) or sheep dogs (region 1). In order to control the rabies virus, a rabies vaccination program for dogs was introduced by the government of Greenland in 1969 (WHO 1990). The program was made mandatory in 1997 and includes both dogs and cats (Mansfield et al. 2006). Since both the Greenlandic sledge dog and the sheep dog are used as working animals, the life expectancy is approx. 5 years resulting in a fast turnover of dogs. Compulsory vaccination of dogs (revaccination every 3 years) represents significant expenses for dog owners and the Greenlandic society in general, and preventive measures to reduce such costs have been explored.

Several studies have indicated the potential for vaccination against rabies in wild animals, thus preventing the infection route to humans, but the long-term efficiency and cost benefits are not obvious (Brochier et al. 1991; Hanlon et al. 1999). Large-scale eradication of rabies in Arctic foxes using bait-vaccination has been 
$\mathbf{a}$

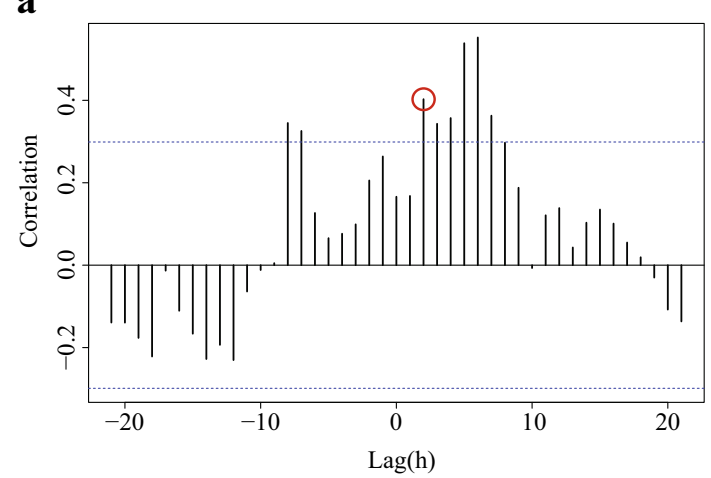

c

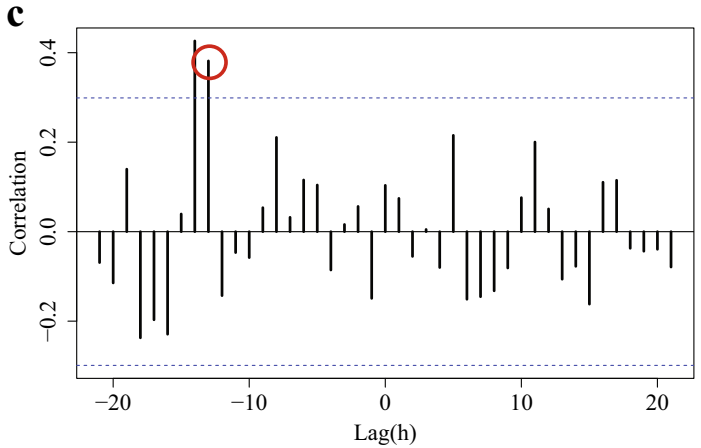

e

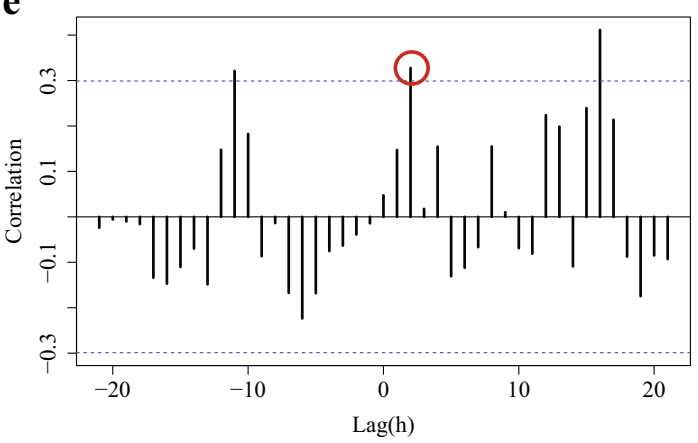

g

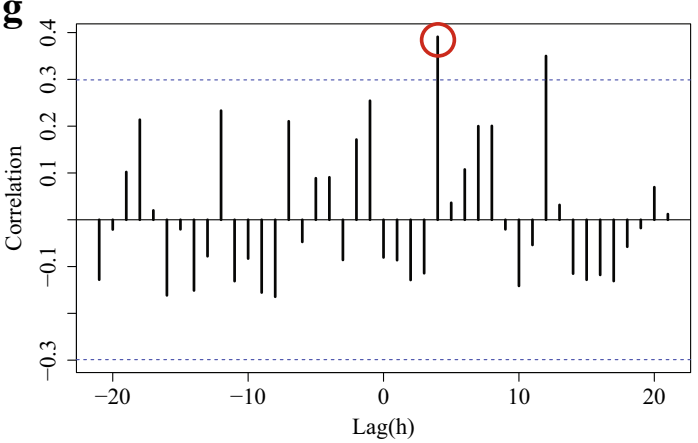

Fig. 3 Cross correlation between yearly outbreaks of rabies in neighboring regions; a regions 1 and 2 , b regions 2 and 3 , $\mathbf{c}$ regions 3 and 4, d regions 4 and 5, e regions 5 and 6, f regions 2 and " $3+4$ ", and $\mathbf{g}$ regions " $3+4$ " and 5. Bars represent the individual cross correlations while dotted vertical lines are levels of statistical significant $(p<0.05)$

considered for Greenland, but due to vast geographical area to be covered, it is not economically or practically feasible (Hansen et al. 1996). Furthermore, the reintroduction of rabies via immigrating foxes from northern b

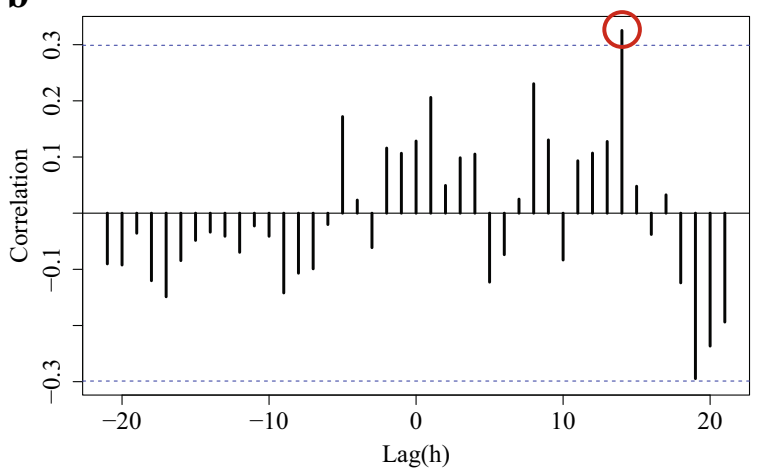

d
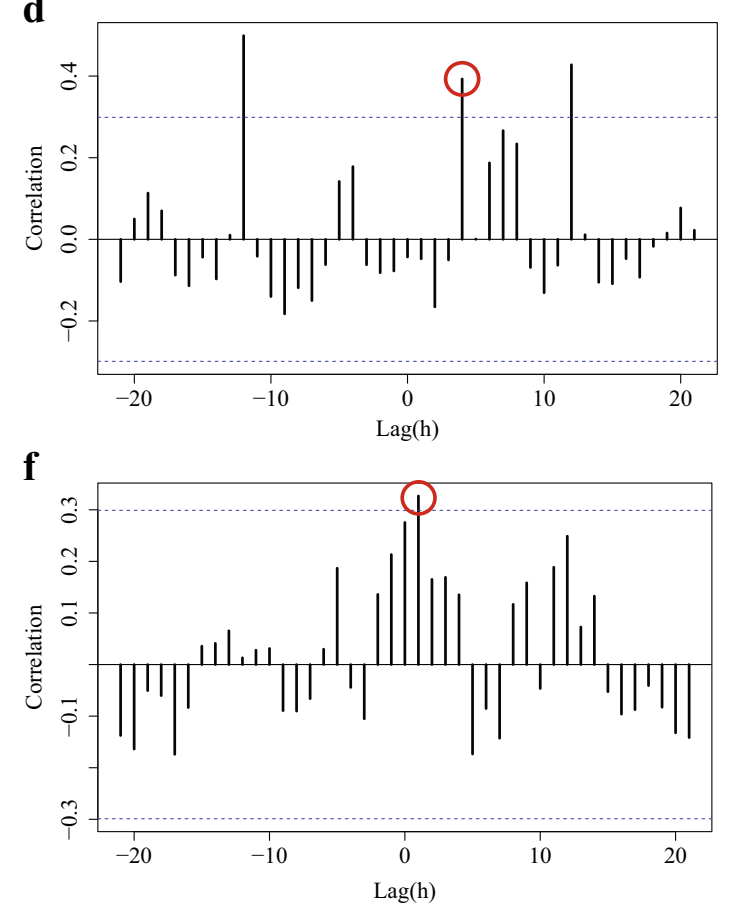

relationships. Outbreaks in neighboring regions are either correlated with positive lags $(h>0)$ indicating that region $\mathrm{x}$ lags region $\mathrm{y}$ or correlated with negative lags $(h<0)$ indicating that region y lags region $\mathrm{x}$. The red markings indicate the relevant significant correlations. For further explanations, please see the text

Canada would most likely repeatedly compromise any local prevention programs.

Although the present study identifies some basic characteristics of the spatiotemporal distribution of Arctic fox rabies in 
Greenland, the transmission principles and timing of the recurrent outbreaks are not known. The severity of the disease, the reduced hunting pressure of the foxes, and the increasing human population suggest the need for a new survey (comparable to the study in 1992/1993) which would allow for a more systematic risk assessment and provide information relevant for stakeholders in Greenland.

Acknowledgment The authors wish to thank the Commission for Scientific Research in Greenland for financial support relating to the fieldwork in 1992/1993. Mads C. Forchhammer is thanked for the support to wavelet analyses and valuable comments to the manuscript. Dr. Leif Rønsholt, State Veterinary Institute for Virus Research, Lindholm, DK4771 Kalvehave, Denmark, is acknowledged for the supervision of the laboratory assays.

\section{References}

Angerbjörn A, Hersteinsson P, Tannerfeldt M (2004) Europe and North and Central Asia (Palearctic)-Arctic fox, Alopex lagopus. In: Sillero-Zubiric C, Hoffmann M, MacDonald DW (eds) Canids: foxes, wolves, jackals and dogs, Status survey and conservation action plan. The Wildlife Conservation Research Unit, Oxford, pp 117123

Ann (2001) Rabies i det sydligste Grønland - historisk oversigt [Rabies in southern Greenland - historical overview]. Grønlands Hjemmestyre, Journ. nr. $47.20 .03+04$

Ballard WB, Follmann EH, Ritter DG, Robards MD, Cronin MA (2001) Rabies and canine distemper in an Arctic fox population in Alaska. J Wildl Dis 37:133-137

Bjerregaard P, Zoffmann H (1986) Rabies i Grønland [Rabies in Greenland]. Ugeskr Laeger 148:143-146 [In Danish with English summary]

Brochier B, Kieny MP, Costy F, Coppens P, Bauduin B, Lecocq JP, Languet B, Chappuis G, Desmettre P, Afiademanyo K, Libois R, Pastoret PP (1991) Large-scale eradication of rabies using recombinant vaccinia-rabies vaccine. Nature 354:520-522

Cazelles B, Chavez M, Berteaux D, Ménard F, Vik JO, Jenouvrier S, Stenseth NC (2008) Wavelet analysis of ecological time series. Oecologia 156:287-304

Christensen LS, Jacobsen K, Mærsk-Møller E (2008) Rabies hos en kat i Grønland [Rabies in a cat in Greenland]. Ugeskr Laeger 170:2584 2585 [In Danish with English summary]

Dalén L, Fuglei E, Hersteinsson P, Kapel CMO, Roth JD, Samelius G, Tannerfeldt M, Angerbjörn A (2005) Population history and genetic structure of a circumpolar species: the Arctic fox. Biol J Linn Soc 84:79-89

Elmhagen B, Hellström P, Angerbjörn A, Kindberg J (2011) Changes in vole and lemming fluctuations in northern Sweden 1960-2008 revealed by fox dynamics. Annls Zool Fennici 48:167-179

Geffen E, Waidyaratne S, Dalén L, Angerbjörn A, Vila C, Hersteinsson P, Fuglei E, White PA, Goltsman M, Kapel CMO, Wayne RK (2007) Sea ice occurence predicts genetic isolation in the Arctic fox. Mol Ecol 16:4241-4255

Goltsman M, Kruchenkova EP, Sergeev S, Johnson PJ, Macdonald DW (2005) Effects of food availability on dispersal and cub sex ratio in the Mednyi Arctic fox. Behav Ecol Sociobiol 59:198-206

Hammer Ø (2015) PAST reference manual. Natural History Museum, University of Oslo, Norway, $225 p$
Hammer Ø, Harper DAT, Ryan PD (2001) PAST paleontological statistics software package for education and data analysis. Palaeontol Electron 4:9p

Hankins DG, Rosekrans JA (2004) Overview, prevention, and treatment of rabies. Mayo Clin Proc 79:671-676

Hanlon CA, Childs JE, Nettles VF, The National Working Group on Rabies Prevention and Control (1999) Recommendations of a national working group on prevention and control of rabies in United States-article III: rabies in wildlife. J Am Vet Med Assoc 215: 1612-1619

Hansen EH, Schyum P, Rose CH, Rønsholt L (1996) Oral vaccination of arctic foxes in Greenland - a field trial. In: Advances towards rabies control in the Americas, VII Annual International Meeting, Atlanta, USA

Jackson AC (2008) Rabies. Neurol Med-Chir 26:717-726

Kapel CMO (1999) Diet of arctic foxes (Alopex lagopus) in Greenland. Arctic 52:289-293

Kapel CMO, Nansen P (1996) Gastrointestinal helminths of arctic foxes (Alopex lagopus) from different bioclimatological regions in Greenland. J Parasitol 82:17-24

Krebs JW, Wilson ML, Childs JE (1995) Rabies - epidemiology, prevention, and future research. J Mammal 76:681-694

Kuzmin IV, Huges GJ, Botvinkin AD, Gribencha SG, Rupprecht CE (2008) Arctic and Arctic-like rabies viruses: distribution, phylogeny and evolutionary history. Epidemiol Infect 136:509-519

Lassen HC (1962) Rabies i Grønland [Rabies in Greenland] Ugeskrift for Læger 124:269-272 [In Danish with English summary]

Leisner K (2002) Rabies in Greenland, 1975-2001. Rabies Bull Eur 26: $10-14$

Leung AKC, Davies HD, Hon K-LE (2007) Rabies: epidemiology, pathogenesis, and prophylaxis. Adv Ther 24:1340-1347

MacDonald E, Handeland K, Blystad H, Bergsaker M, Fladberg M, Gjerset B, Nilsen O, Os H, Sandbu S, Stokke E, Vold L, Ørpetveit I, Åmot HG, Tveiten O (2011) Public health implications of an outbreak of rabies in arctic foxes and reindeer in the Svalbard archipelago, Norway, September 2011. Euro Surveill 16:4 p

Mallat S (2008) A wavelet tour of signal processing: The sparse edition. 3rd edn. Academic Press, p 123

Mansfield KL, Racloz V, McElhinney LM, Marston DA, Johnson N, Rønsholt L, Christensen LS, Neuvonen E, Botvinkin AD, Rupprecht CE, Fooks AR (2006) Molecular epidemiological study of Arctic rabies virus isolates from Greenland and comparison with isolates from throughout the Arctic and Baltic regions. Virus Res 116:1-10

Meinke PG, Kapel CMO, Arctander P (2001) Genetic differentiation of populations of Greenlandic Arctic fox. Polar Res 20:75-83

Ménard F, Marsac F, Bellier E, Cazelles B (2007) Climatic oscillations and tuna catch rates in the Indian Ocean: a wavelet approach to time series analysis. Fish Oceanogr 16:95-104

Mørk T, Prestrud P (2004) Arctic rabies - a review. Acta Vet Scan 45:1-9

Mørk T, Bohlin J, Fuglei E, Åsbakk K, Tryland M (2011) Rabies in the Arctic fox population, Svalbard, Norway. J Wildl Dis 47:945-957

Nadin-Davis S, Muldoon F, Whitney H, Wandeler AI (2008) Origins of the rabies viruses associated with an outbreak in Newfoundland during 2002-2003. J Wildl Dis 44:86-98

Nadin-Davis S, Sheen M, Wandeler AI (2012) Recent emergence of the Arctic rabies virus lineage. Virus Res 163:352-362

Norén K, Carmichael L, Dalén L, Hersteinsson P, Samelius G, Fuglei E, Kapel CMO, Menyushina I, Strobeck C, Angerbjörn A (2011a) Arctic fox Vulpes lagopus population structure: circumpolar patterns and processes. Oikos 120:873-885

Norén K, Carmichael L, Fuglei E, Eide NE, Hersteinsson P, Angerbjörn A (2011b) Pulses of movement across the sea ice: population connectivity and temporal genetic structure in the arctic fox. Oecologia 166:973-984 
Odegaard ØA, Krogsrud J (1981) Rabies in Svalbard: infection diagnosed in arctic fox, reindeer and seal. Vet Rec 109:41-142

Pagh S, Hersteinsson P (2008) Difference in diet and age structure of blue and white Arctic foxes (Vulpes lagopus) in the Disko Bay area, West Greenland. Polar Res 27:44-51

Prestrud P, Krogsrud J, Gjertz I (1992) The occurrence of rabies in the Svalbard Islands of Norway. J Wildl Dis 28:57-63

Rausch R (1958) Some observations on rabies in Alaska, with special reference to wild canidae. J Wildl Manage 22:246-260

Robles CG, Miranda NLJ (1992) Comparative evaluation of the rabies fluorescent antibody test and direct microscopic examination at the Research Institute for Tropical Medicine. PSMID 21:46-50

Sokal RR, Rohlf FJ (2001) Biometry: the principles and practice of statistics in biological research. 3rd edition, W.H. Freemann and Company, $887 \mathrm{p}$

Sundelöf A, Bartolino V, Ulmestrand M, Cardinale M (2013) Multiannual fluctuations in reconstructed historical time-series of a
European lobster (Homarus gammarus) population disappear at increased exploitation levels. PLOSOne 8:e58160

Tabel H, Corner AH, Webster WA, Casey CA (1974) History and epizootiology of rabies in Canada. Can Vet J 15:271-281

Tarroux A, Berteaux D, Bêty J (2010) Northern nomads: ability for extensive movements in adult arctic foxes. Polar Biol 33:10211026

Tinline RR, MacInnes CD (2004) Ecogeographic patterns of rabies in Southern Ontario based on time series analysis. J Wildl Dis 40: 212-221

WHO, World Health Organization (1990) Report of a WHO/NVI workshop on Arctic rabies. WHO/Rab. Res/90.35, Uppsala, Sweden

WHO, World Health Organization (2004) WHO Expert Consultation on Rabies: first report. WHO Technical report series no. 931

Woldehiwet Z (2005) Clinical laboratory advances in the detection of rabies virus. Clin Chim Acta 351:49-63 